\title{
Mass mortality of Canthigaster rostrata at the northeast coast of the Yucatan Peninsula
}

Received: 24 December 2008/Accepted: 7 March 2009/Published online: 24 March 2009

(C) Springer-Verlag 2009

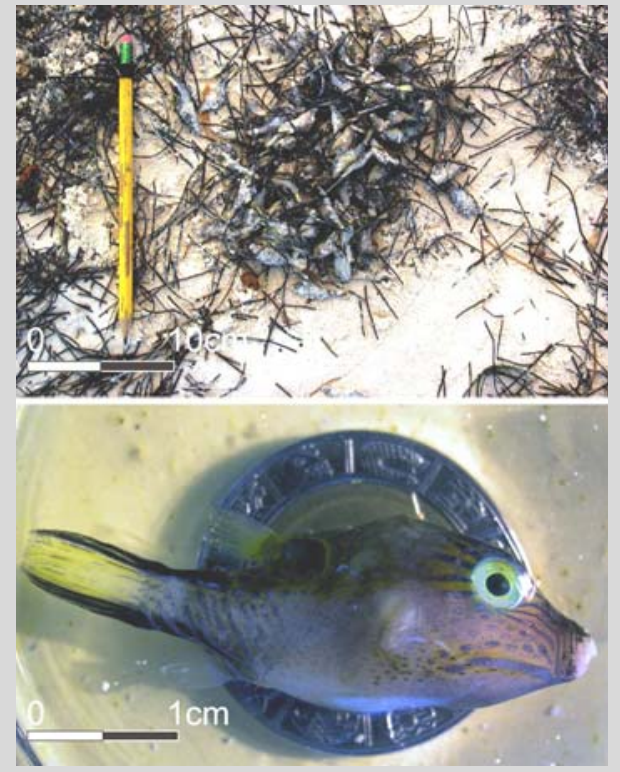

Fig. 1 Dead and dying fishes that were washed ashore (top) with no evident signs of disease (bottom)
On December 2008 a mass-mortality event affecting the sharpnose puffer, Canthigaster rostrata, was observed at several locations along the northeast coast of the Yucatan Peninsula. Dead and dying fishes were washed ashore periodically between December 6 and 18 (Fig. 1). Dead fishes desiccated during the day allowing the differentiation of recurring episodes of demise. The first observations were made on December 6 around Akumal and 2 days later at Puerto Morelos, $70 \mathrm{~km}$ down-current. Later reports originated from several locations along a $100-\mathrm{km}$ section of the northeast coast. Recently dead fishes were washed ashore with the highest frequency of $39.5 \pm 23.6$ (mean \pm SD) dead fishes per $\mathrm{m}^{2}$ (in four $3 \mathrm{~m}^{2}$ belt transects) at Puerto Morelos. Fishes were dissected for signs of disease on the skin and organs, but none was found. Fishes had a maximum length of $3.8 \pm 0.26 \mathrm{~cm}$ (mean $\pm \mathrm{SD}, n=47$ ), being about half the size of the smaller reproductive adults reported by Sikkel (1990) and, given their small range in size, they were probably juveniles from a single cohort.

\section{Reference}

Sikkel PC (1990) Social organization and spawning in the Atlantic sharpnose puffer, Canthigaster rostrata (Tetraodontidae). Environ Biol Fish 27:243-254

A. G. Jordán-Garza $(\bowtie) \cdot$ E. M. Díaz-Almeyda · R. Iglesias-Prieto

Instituto de Ciencias del Mar y Limnología, Universidad Nacional Autónoma de México, Ap. Postal 1152, 77500 Cancun, Quintana Roo, Mexico

e-mail: jorga1@yahoo.com

M. A. Maldonado $\cdot$ J. Ortega

Centro Ecológico Akumal, Ap. Postal 2, 77760 Akumal, Quintana Roo, México 